\title{
THE EFFECT OF ETHANOL ON THE VENTILATORY RESPONSES MEDIATED BY THE PERIPHERAL CHEMORECEPTORS IN MAN
}

\author{
J. Duffin, E.R. Jacobson, and E.C. Orsini
}

THE EFFECT of depressant drugs such as anaesthetics on the ventilatory responses mediated by the peripheral chemoreceptors is of considerable interest to anaesthetists because such depression threatens the physiological defence against hypoxia. In fact, because of the complex response of the peripheral chemoreceptors, their depression threatens not only the ventilatory response to hypoxia, but also the rapidly acting portion of the ventilatory response to carbon dioxide.

Indirect tests of peripheral chemoreceptor responsiveness to hypoxia and carbon dioxide have shown that whereas thiopentone produces little depression of these responses, halothane produces considerable depression. 1.2 One of the hypotheses considered was that the general vasodilation associated with halothane may have caused an increased blood flow through the peripheral chemoreceptors, thereby decreasing their responsiveness. In order to provide collaborating evidence on this hypothesis it was decided to test the responsiveness of the peripheral chemoreceptors in the presence of ethanol, whose known properties include general depression and vasodilation in man. In addition, it was felt that in view of the wide use of ethanol both socially and clinically, the measurement of its effects on the ventilatory responses mediated by the peripheral chemoreceptors would prove to be of general interest.

Although a number of investigators (Mackenzie and Hill, ${ }^{3}$ Higgins, ${ }^{4}$ Hitchcock, ${ }^{5}$ Johnstone and $W^{\prime}\left(t^{6}\right)$ have studied the effects of ethanol on ventilation, it is difficult to reach a clear conclusion with respect to its effects. Johnstone and $\operatorname{Reier}^{7}$ found that the ventilatory response to carbon dioxide under hyperoxic conditions, in which the peripheral chemoreceptors are virtually silent, was shifted to higher levels of carbon

J. Duffin, Ph.D., Associate Professor; E.R. Jacobson, Student Research Assistant; and E.C. Orsini, Student Research Assistant. Departments of Anaesthesia and Physiology, Faculty of Medicine, University of Toronto.

Address correspondence to: Dr. J. Duffin, Department of Physiology, Medical Sciences Building, University of Toronto, Toronto, Canada, M5S 1A8.

Canad. Anaesth. Soc. J., vol. 25, no. 3, May 1978 dioxide with little change in slope (sensitivity). Sahn, Lakshminarayan, Pierson and Weil ${ }^{8}$ tested the response to hypoxia in isocapnic conditions, which is mediated by the peripheral chemoreceptors, and the response to carbon dioxide in hyperoxic conditions, which is mediated by the central chemoreceptors. They found that both types of response were depressed but at different times.

This study assesses the effects of orally administered ethanol on the ventilatory responses mediated by both the central and the peripheral chemoreceptors. The peripheral chemoreceptor stimulus used is a combination of increasing carbon dioxide and decreasing oxygen, a physiological stimulus which produces the maximum ventilatory responses because of synergistic interaction. ${ }^{9}$

\section{METHODS}

Eight healthy volunteers (five males and three females) between 19 and 30 years of age were studied. They were recruited by personal contact from the University, but none were familiar with respiratory physiology. All of them answered a questionnaire and were accepted for the study only if they had no previous history of respiratory, cardiovascular or gastro-intestinal disorders and were not taking medication of any kind. The volunteers were informed as to the conditions of the experiment and their consequences before signing a consent form, which allowed them to withdraw from the tests at any time, but would restrict them from leaving the laboratory until judged to be free of the intoxicating effects of the ethanol. They were studied at least six hours after the ingestion of food or caffeinated drink either in the morning omitting breakfast (most) or in the afternoon omitting lunch.

The ventilatory responses of the central and peripheral chemoreceptors were assessed using two rebreathing tests, one in hyperoxic conditions (Read $\left.{ }^{10}\right)$, and the other in hypoxic conditions. In the latter rebreathing test, ventilation is stimulated by the simultaneous increase in car- 
bon dioxide and decrease in oxygen which acts at both central and peripheral chemoreceptors. In the hyperoxic rebreathing test, ventilation is stimulated by the increase in carbon dioxide which acts primarily at the central chemoreceptors. The difference between the ventilatory responses to these two rebreathing tests is, therefore, an index of the ventilatory response to simultaneously rising carbon dioxide and falling oxygen mediated by the peripheral chemoreceptors.

The volunteers followed a strict protocol of testing which was prefaced by a hypoxic rebreathing test for the purpose of familiarization. The volunteers were then assessed with both the hyperoxic and hypoxic rebreathing tests (Test Set I). The order in which the tests were done was fixed for each volunteer but alternated between volunteers. Each rebreathing test took about 10 minutes, with a 15 -minute rest after each test. The volunteers then consumed $0.75 \mathrm{ml}$ ethanol per $\mathrm{kg}$ body weight in a 20 per cent solution with orange juice over a 15 -minute period. The rebreathing tests were then repeated between 5 and 40 minutes after ethanol (Test Set II) and between 75 and 115 minutes after ethanol (Test Set III). Before and after each rebreathing test duplicate breathalyser (CMl Intoxalyser 4011) measurements of end-tidal ethanol concentration were made as an estimate of the blood levels of ethanol.

During all of the rebreathing tests, the volunteers sat in a comfortable chair listening to "classical" music through earphones and breathing through a low resistance 3-way " $Y$ " valve (Collins P-319). One side of the " $Y$ " valve was connected to a T-piece, through which controlled gas compositions flowed from a set of rotameters, at a sufficient flow to prevent rebreathing. The other side of the "Y" valve was connected to the rebreathing bag. The rebreathing bag was enclosed in a rigid box which was connected to a spirometer (Med. Sci. . 270 Wedge) by wide bore $(3.8 \mathrm{~cm}$; 1.5 inch) tubing. Breath-by-breath volume and flow were obtained from the spirometer and recorded on a multi-channel recorder (HPSanborn) at a paper speed of $10 \mathrm{~mm} / \mathrm{s}$ during the breathing tests and at $1 \mathrm{~mm} / \mathrm{s}$ during the 5 -minute equilibration period before each test and the period of carbon dioxide removal after each test. Carbon dioxide and oxygen were also monitored continuously at the mouth (Godart 146 Capnograph and Westinghouse $211 \mathrm{M} \mathrm{Oxygen} \mathrm{Analyser,}$ respectively) and recorded. It should be noted that the oxygen analyser used here was not of

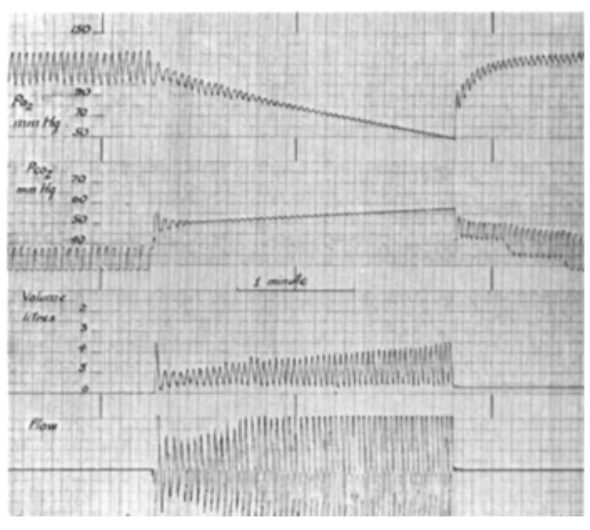

FIgure 1, Recordings of oxygen and carbon dioxide levels, and lung volume and flow changes during a typical hypoxic rebreathing test.

sufficiently fast response to record end-tidal $\mathrm{PO}_{2}$ (see Figure 1), except under the conditions of rebreathing where the changes were small.

The hyperoxic rebreathing test used in these experiments was that described by Read. ${ }^{10}$ The rebreathing bag was filled to 1 litre more than the volunteer's vital capacity with a mixture containing 50 per cent oxygen, 43 per cent nitrogen and seven per cent carbon dioxide. The volunteers were studied in a seated position and, after breathing a hyperoxic mixture containing 50 per cent oxygen and 50 per cent nitrogen from a set of rotameters through the $\mathrm{T}$-piece for five minutes, and when stable $\mathrm{PCO}_{2}$ and $\mathrm{PO}_{2}$ readings were obtained, they were switched with the " $Y$ " valve, from the T-piece to the rebreathing bag. They rebreathed for a period of four minutes or until discomfort was felt, and were then switched from the bag to the T-piece through which a controlled gas composition flowed from the rotameters, with $\mathrm{PCO}_{2}$ adjusted to be similar to that at the end of rebreathing. The $\mathrm{PCO}_{2}$ was then gradually reduced to zero.

The hypoxic rebreathing test used in these experiments was similar to the hyperoxic test ex cept that air substituted for hyperoxia. The rebreathing bag was filled with a mixture containing seven per cent carbon dioxide in air $(7$ per cent $\mathrm{CO}_{2}, 19.5$ per cent $\mathrm{O}_{2}, 73.5$ per cent $\mathrm{N}_{2}$ ) and the volunteers breathed air during the five-minute equilibration period before the test. They rebreathed until end-tidal $\mathrm{PO}_{2}$ fell to $6.67 \mathrm{kPa}$ $(50 \mathrm{~mm} \mathrm{Hg})$ or until discomfort was felt. Figure 1 shows the chart record from a hypoxic rebreathing test recorded at a slow speed so that the entire test could be viewed. 
TABLE I

The Physical Characteristics of the Volunteers and the End-Tidal Levels of Ethanol Before and After the Second and Third Sets of Rebreathing Tests (Expressed as Equivalent Blood Levels)

\begin{tabular}{|c|c|c|c|c|c|c|c|c|}
\hline \multirow[b]{3}{*}{ Volunteer } & \multirow[b]{3}{*}{ Sex } & \multirow{3}{*}{$\begin{array}{c}\text { Weight } \\
(\mathrm{kg})\end{array}$} & \multirow{3}{*}{$\begin{array}{l}\text { Age } \\
\text { (yrs) }\end{array}$} & \multirow{3}{*}{$\begin{array}{c}\text { Vital } \\
\text { Capacity } \\
\text { litres } \\
\text { BTPS }\end{array}$} & \multicolumn{4}{|c|}{ Ethanol level $\mathrm{mg} / 100 \mathrm{ml}$} \\
\hline & & & & & \multicolumn{2}{|c|}{ Test Set II } & \multicolumn{2}{|c|}{ Test Set III } \\
\hline & & & & & Before & After & Before & After \\
\hline F.C. & $\mathbf{M}$ & 73 & 25 & 5.1 & 63 & 46 & 50 & 35 \\
\hline C.L. & $\mathbf{F}$ & 59 & 23 & 3.8 & 53 & 72 & 70 & 52 \\
\hline K.H. & $\mathbf{M}$ & 84 & 24 & 5.6 & 87 & 60 & 51 & 39 \\
\hline S.G. & $\mathbf{M}$ & 80 & 30 & 5.6 & 79 & 71 & 63 & 49 \\
\hline S.S. & $\mathbf{F}$ & 59 & 19 & 3.9 & 70 & 65 & 64 & 51 \\
\hline L.M. & $\mathbf{M}$ & 91 & 20 & 5.2 & 18 & 47 & 48 & 47 \\
\hline B.H. & $\mathbf{M}$ & 80 & 24 & 5.3 & 28 & 49 & 47 & 34 \\
\hline P.O. & $\mathbf{F}$ & 59 & 23 & 3.9 & 61 & 55 & 49 & 36 \\
\hline $\begin{array}{l}\text { Mean } \\
\pm 1 \text { SEM }\end{array}$ & & & & & $\begin{array}{c}57 \\
\pm 8.4\end{array}$ & $\begin{array}{c}58 \\
\pm 3.7\end{array}$ & $\begin{array}{l}55 \\
+3.2\end{array}$ & $\begin{array}{c}43^{*} \\
\pm 2.7\end{array}$ \\
\hline
\end{tabular}

*Significantly different from the previous value at the one per cent level by paired t-test.

For both of the rebreathing tests. the occurrence of a carbon dioxide plateau, indicating equilibrium had been reached, was essential for the continuation of the test; otherwise it was repeated with a different carbon dioxide concentration in the bag. Following the point of carbon dioxide equilibration, tidal volume was measured from the volume trace, breath period was measured from the flow trace and $\mathrm{PCO}_{2}$ and $\mathrm{PO}_{2}$ values were measured from their individual traces. Ventilation (BTPS) was calculated on a breath-bybreath basis and plotted against $\mathrm{PCO}_{2}$ for each test, and, in the case of the hypoxic rebreathing test, ventilation was also plotted against $\mathrm{Po}_{2}$. Linear regression lines were calculated for each plot.

\section{RESULTS}

Each volunteer consumed enough ethanol to produce a mild euphoria and only one exceeded the Ontario legal limit for drivers of $80 \mathrm{mg} /$ $100 \mathrm{ml}$. Because the ethanol was administered orally, there was a wide variation in the initial levels of alcohol between volunteers. Table I details the physical characteristics of the volunteers and the ethanol levels before and after test sets II and III. A more detailed presentation of the ethanol variation between volunteers and the time course throughout the experiment is shown in Figure 2.

Breath-by-breath graphs of ventilation against end-tidal $\mathrm{PCO}_{2}$ were made for each rebreathing test so that they could be compared by inspection. Each graph was fitted with a linear regres-

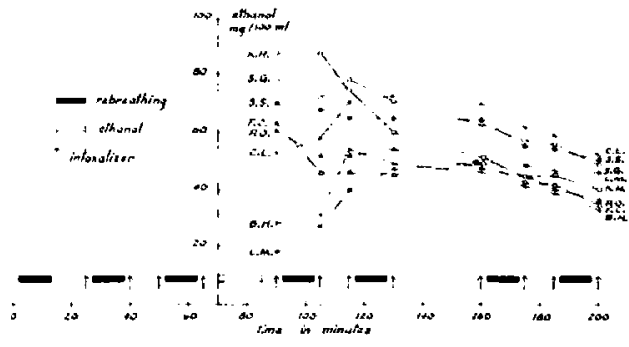

Figure 2. A plot of end-tidal ethanol in terms of blood level in $\mathrm{mg} / 100 \mathrm{~m} /$ versus time in minutes for all of the volunteers. The horizontal bats show the time of consumption of ethanol and of the rebreathing tests.

sion line. Figures 3, 4 and 5 show these graphs of volunteer S.S. for the rebreathing tests of test sets I, II and III, respectively. The results of volunteer S.S. are typical of the responses from most volunteers.

Table II lists the slopes, intercepts and regression coefficients of ventilation against end-tidal $\mathrm{PCO}_{2}$ for the control rebreathing tests (test set I). Tables III and IV provide the same information for the rebreathing tests of test sets II and III respectively. The mean slope $( \pm 1 \mathrm{SEM})$ of the ventilation against end-tidal $\mathrm{PCO}_{2}$ lines for the first hyperoxic rebreathing tests under control conditions was $3.8 \pm 0.54 \mathrm{litres} / \mathrm{min} / \mathrm{mm} \mathrm{Hg}$. For the second set of tests, at about 25 minutes after ethanol, the mean slope was $3.9 \pm 0.57$ litres/ $\mathrm{min} / \mathrm{mm} \mathrm{Hg}$, and for the third set of tests, at about 95 minutes after ethanol, the mean slope was 4.2 \pm 0.99 litres $/ \mathrm{min} / \mathrm{mm} \mathrm{Hg}$. Neither of these values after ethanol are significantly different from the 


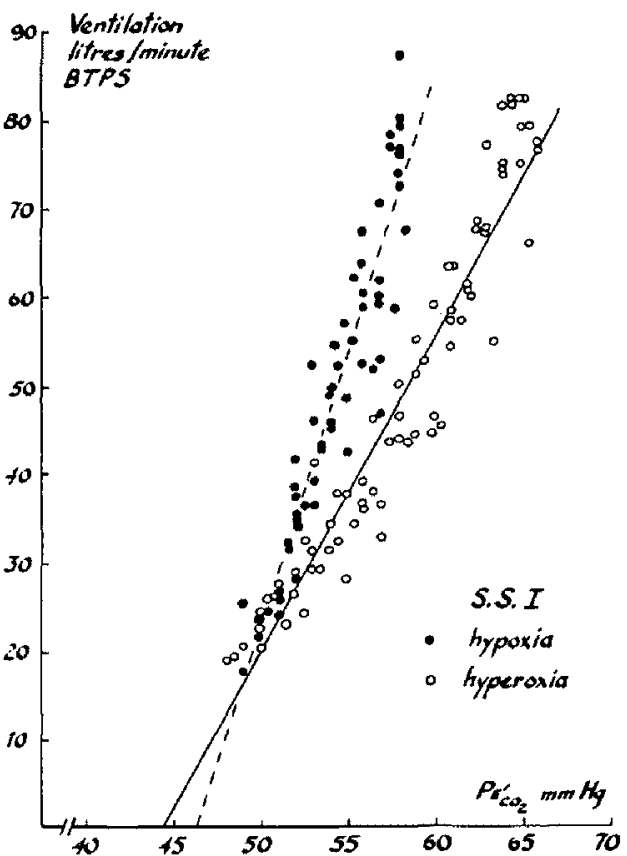

Figure 3. A plot of breath-by-breath values of ventilation in litres per minute (BTPS) versus end-tidal $\mathrm{PCO}_{2}\left(\mathrm{PE}_{\mathrm{CO}_{2}}^{\prime}\right)$ for volunteer S.S. during the rebreathing tests of test set $I$.

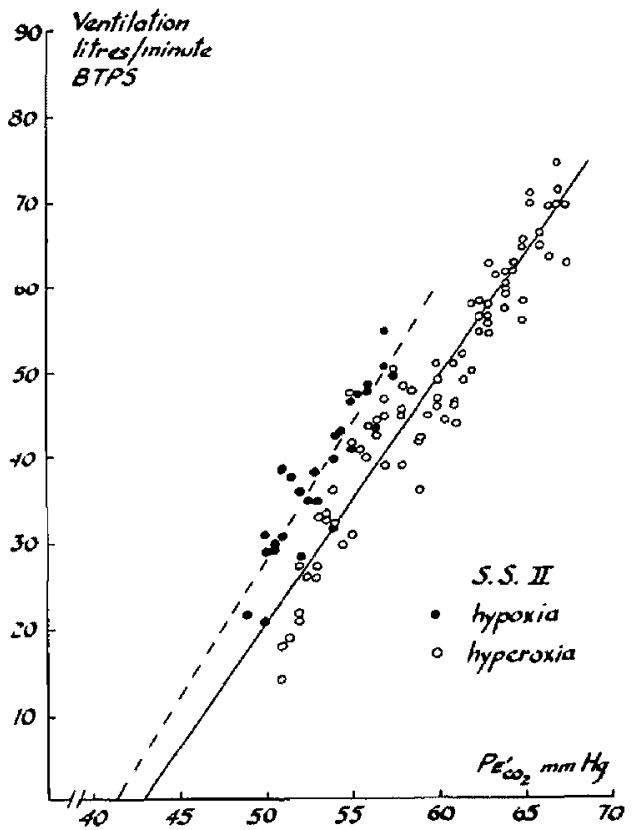

FIGURE 4. A plot of breath-by-breath values of ventilation in litres per minute (BTPS) versus end-tidal $\mathrm{PCO}_{2}\left(\mathrm{PE}^{\prime} \mathrm{CO}_{2}\right)$ for volunteer S.S. during the rebreathing tests of test set II.

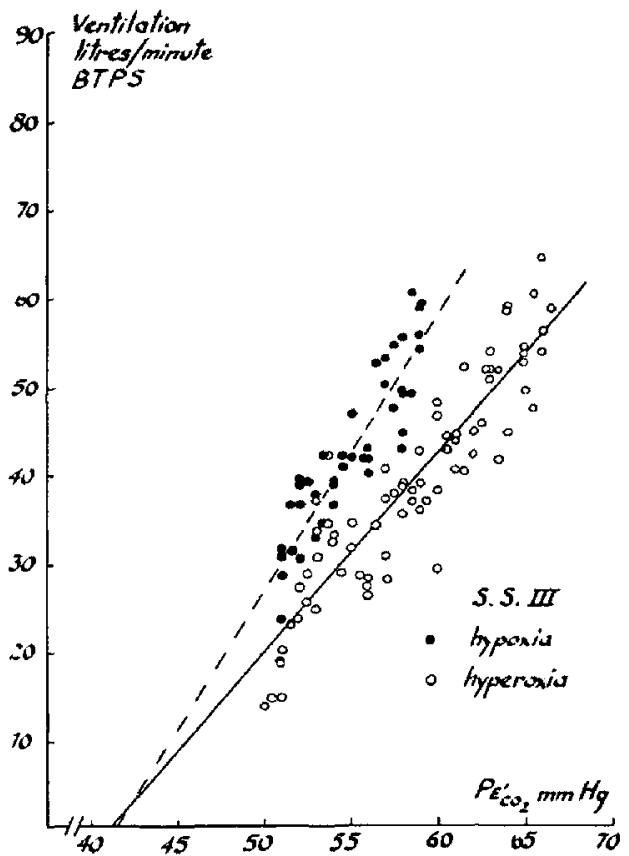

FIGURE 5. A plot of breath-by-breath values of ventilation in litres per minute (BTPS) versus end-tidal $\mathrm{PCO}_{2}\left(\mathrm{PE}^{\prime} \mathrm{CO}_{2}\right)$ for volunteer S.S. during the rebreathing tests of test set III.

control value by paired t-testing. Since this slope is an index of the ventilatory response to carbon dioxide mediated by the central chemoreceptors, it was concluded that ethanol had not impaired this response.

The mean slope $( \pm 1$ SEM) of the ventilation against end-tidal $\mathrm{PCO}_{2}$ lines for the first hypoxic rebreathing tests under control conditions was $7.5 \pm 0.75$ litres $/ \mathrm{min} / \mathrm{mm} \mathrm{Hg}$. For the second set of tests, at about 25 minutes after ethanol, the mean slope decreased to $5.5 \pm 0.92$ litres/ $\mathrm{min} / \mathrm{mm} \mathrm{Hg}$, and for the third set of tests, at about 95 minutes after ethanol, the mean slope remained at $5.5 \pm 0.85 \mathrm{litres} / \mathrm{min} / \mathrm{mm} \mathrm{Hg}$. While the first value after ethanol is significantly different from the control value at the five per cent probability level by paired t-testing, the second value is not. This slope is an index of the ventilatory response to simultaneously rising carbon dioxide and falling oxygen mediated by both the peripheral and the central chemoreceptors.

The mean difference $( \pm 1$ SEM) in the slopes of the ventilation against end-tidal $\mathrm{PCO}_{2}$ lines between the hypoxic and hyperoxic rebreathing tests under control conditions was $3.8 \pm 0.82$ litres $/ \mathrm{min} / \mathrm{mm} \mathrm{Hg}$. For the second set of tests at about 25 minutes after ethanol, the mean differ- 
TABLE II

Test Set I. The Characteristics of the Regression Lines for the Breath-By-Breath Graphs of Ventilation (BTPS) Versus End-Tidal PCO $\mathrm{PF}_{2}$ All the Volunteers in the CONTrOl Tests of Test Set I

\begin{tabular}{|c|c|c|c|c|c|c|c|}
\hline \multirow[b]{2}{*}{ Volunteer } & \multicolumn{3}{|c|}{ Hypoxic rebreathing } & \multicolumn{3}{|c|}{ Hyperoxic rebreathing } & \multirow{2}{*}{$\begin{array}{c}\text { Difference } \\
\text { in slope } \\
1 / \mathrm{min} / \mathrm{mm} \mathrm{Hg}\end{array}$} \\
\hline & $\begin{array}{c}\text { Slope } \\
\text { l/min/mm Hg }\end{array}$ & $\begin{array}{l}\text { Intercept } \\
\mathrm{mm} \mathrm{Hg}\end{array}$ & $\mathbf{r}$ & $\begin{array}{c}\text { Slope } \\
1 / \mathrm{min} / \mathrm{mm} \mathbf{H g}\end{array}$ & $\begin{array}{r}\text { Intercept } \\
\text { mm Hg }\end{array}$ & $\mathbf{r}$ & \\
\hline $\begin{array}{l}\text { F.C. }{ }^{1} \\
\text { C.L. }{ }^{2} \\
\text { K.H. }{ }^{1} \\
\text { S.G. } \\
\text { S.S. }^{1} \\
\text { L.M. }^{2}{ }^{2} \\
\text { B.H. }{ }^{1} \\
\text { P.O. }{ }^{2}\end{array}$ & $\begin{array}{r}5.6 \\
9.7 \\
5.6 \\
5.5 \\
6.2 \\
9.0 \\
10.8 \\
7.9\end{array}$ & $\begin{array}{l}49.7 \\
43.5 \\
46.6 \\
45.4 \\
46.4 \\
42.8 \\
51.3 \\
47.3\end{array}$ & $\begin{array}{l}0.96 \\
0.97 \\
0.98 \\
0.96 \\
0.93 \\
0.92 \\
0.92 \\
0.96\end{array}$ & $\begin{array}{l}2.7 \\
5.3 \\
3.9 \\
2.3 \\
3.6 \\
6.0 \\
1.6 \\
4.7\end{array}$ & $\begin{array}{l}47.2 \\
41.7 \\
44.1 \\
40.9 \\
44.5 \\
46.0 \\
38.2 \\
45.5\end{array}$ & $\begin{array}{l}0.98 \\
0.98 \\
0.98 \\
0.95 \\
0.96 \\
0.95 \\
0.84 \\
0.93\end{array}$ & $\begin{array}{l}2.9 \\
4.4 \\
1.7 \\
3.2 \\
2.6 \\
3.0 \\
9.2 \\
3.2\end{array}$ \\
\hline $\begin{array}{l}\text { Mean } \\
\pm 1 \mathrm{SEM}\end{array}$ & $\begin{aligned} & 7.5 \\
\pm & 0.74\end{aligned}$ & $\begin{array}{c}46.6 \\
\pm 1.02\end{array}$ & & $\begin{array}{r}3.8 \\
\pm 0.54\end{array}$ & $\begin{array}{l}43.5 \\
\pm 1.06\end{array}$ & & $\begin{aligned} & 3.8 \\
\pm & 0.82\end{aligned}$ \\
\hline
\end{tabular}

${ }^{1}$ hypoxic rebreathing before hyperoxic rebreathing.

${ }^{2}$ hyperoxic rebreathing before hypoxic rebreathing.

TABLE III

Test Set II. The Characteristics of the Regression Lines For the Breath-By-Breath Graphs of VentilaTION (BTPS) Versus ENd-Tidal PCO ${ }_{2}$ OF All the Volunteers in the Rebreathing Tests of Test Set II

\begin{tabular}{|c|c|c|c|c|c|c|c|}
\hline \multirow[b]{2}{*}{ Volunteer } & \multicolumn{3}{|c|}{ Hypoxic rebreathing } & \multicolumn{3}{|c|}{ Hyperoxic rebreathing } & \multirow{2}{*}{$\begin{array}{c}\text { Difference } \\
\text { in slope } \\
1 / \mathrm{min} / \mathrm{mm} \mathrm{Hg}\end{array}$} \\
\hline & $\begin{array}{c}\text { Slope } \\
\text { 1/min/mm Hg }\end{array}$ & $\begin{array}{l}\text { Intercept } \\
\mathrm{mm} \mathrm{Hg}\end{array}$ & $\mathbf{r}$ & $\begin{array}{c}\text { Slope } \\
1 / \mathrm{min} / \mathrm{mm} \mathbf{H g}\end{array}$ & $\begin{array}{c}\text { Intercept } \\
\mathrm{mm} \mathrm{Hg}\end{array}$ & $\mathbf{r}$ & \\
\hline $\begin{array}{l}\text { F.C. } \\
\text { C.L. } \\
\text { K.H. } \\
\text { S.G. } \\
\text { S.S. } \\
\text { L.M. } \\
\text { B.H. } \\
\text { P.O. }\end{array}$ & $\begin{array}{r}4.0 \\
7.8 \\
4.4 \\
2.4 \\
3.2 \\
10.1 \\
5.4 \\
7.1\end{array}$ & $\begin{array}{l}47.3 \\
43.2 \\
41.9 \\
39.0 \\
41.4 \\
42.8 \\
46.8 \\
44.8\end{array}$ & $\begin{array}{l}0.96 \\
0.93 \\
0.93 \\
0.86 \\
0.92 \\
0.93 \\
0.84 \\
0.92\end{array}$ & $\begin{array}{l}2.7 \\
5.3 \\
4.0 \\
2.2 \\
2.9 \\
5.7 \\
2.1 \\
6.0\end{array}$ & $\begin{array}{l}45.5 \\
40.7 \\
42.5 \\
38.2 \\
43.1 \\
39.2 \\
41.9 \\
40.8\end{array}$ & $\begin{array}{l}0.97 \\
0.98 \\
0.98 \\
0.92 \\
0.95 \\
0.73 \\
0.86 \\
0.96\end{array}$ & $\begin{array}{l}1.3 \\
2.5 \\
0.4 \\
0.2 \\
0.3 \\
4.4 \\
3.3 \\
1.1\end{array}$ \\
\hline $\begin{array}{l}\text { Mean } \\
\pm 1 \text { SEM }\end{array}$ & $\begin{array}{r}5.5^{*} \\
+0.92\end{array}$ & $\begin{array}{c}43.4 \dagger \\
\pm 0.989\end{array}$ & & $\begin{array}{l}3.9 \\
\pm 0.57\end{array}$ & $\begin{array}{l}41.5 \\
+0.813\end{array}$ & & $\begin{array}{r}1.7^{*} \\
\pm 0.55\end{array}$ \\
\hline
\end{tabular}

*Significantly different from Set $\mathbf{I}$ at the five per cent level by paired $t$-test.

†Significantly different from Set $I$ at the one per cent level by paired t-test.

TABLE IV

Test Set III. The Characteristics of the Regression Lines For the Breath-By-Breath Graphs of Ventilation (BTPS) Versus End-Tidal PCO ${ }_{2}$ OF All the Volunteers in the Rebreathing Tests of Test SeT III

\begin{tabular}{|c|c|c|c|c|c|c|c|}
\hline \multirow[b]{2}{*}{ Volunteer } & \multicolumn{3}{|c|}{ Hypoxic rebreathing } & \multicolumn{3}{|c|}{ Hyperoxic rebreathing } & \multirow{2}{*}{$\begin{array}{c}\text { Difference } \\
\text { in slope } \\
\text { 1/min/mm } \mathrm{Hg}\end{array}$} \\
\hline & $\begin{array}{c}\text { Slope } \\
\mathrm{l} / \mathrm{min} / \mathrm{mm} \mathrm{Hg}\end{array}$ & $\begin{array}{l}\text { Intercept } \\
\mathrm{mm} \mathrm{Hg}\end{array}$ & $\mathbf{r}$ & $\begin{array}{c}\text { Slope } \\
\text { l/min/mm } \mathrm{Hg}\end{array}$ & $\begin{array}{c}\text { Intercept } \\
\mathrm{mm} \mathbf{H g}\end{array}$ & $\mathbf{r}$ & \\
\hline $\begin{array}{l}\text { F.C. } \\
\text { C.L. } \\
\text { K.H. } \\
\text { S.G. } \\
\text { S.S. } \\
\text { L.M. } \\
\text { B.H. } \\
\text { P.O. }\end{array}$ & $\begin{array}{l}3.2 \\
8.4 \\
5.5 \\
4.0 \\
3.1 \\
6.6 \\
4.0 \\
9.4\end{array}$ & $\begin{array}{l}46.2 \\
44.6 \\
45.7 \\
43.0 \\
41.5 \\
38.1 \\
45.9 \\
46.9\end{array}$ & $\begin{array}{l}0.97 \\
0.96 \\
0.93 \\
0.95 \\
0.89 \\
0.92 \\
0.84 \\
0.88\end{array}$ & $\begin{array}{r}2.1 \\
5.1 \\
4.2 \\
2.8 \\
2.3 \\
5.0 \\
1.8 \\
10.3\end{array}$ & $\begin{array}{l}43.7 \\
43.5 \\
44.6 \\
43.0 \\
41.3 \\
39.9 \\
39.1 \\
47.7\end{array}$ & $\begin{array}{l}0.90 \\
0.96 \\
0.98 \\
0.93 \\
0.91 \\
0.90 \\
0.85 \\
0.92\end{array}$ & $\begin{array}{r}1.1 \\
3.3 \\
1.3 \\
1.2 \\
0.8 \\
1.6 \\
2.2 \\
-0.9\end{array}$ \\
\hline $\begin{array}{l}\text { Mean } \\
\pm 1 \text { SEM }\end{array}$ & $\begin{array}{r}5.5^{*} \\
\pm 0.85\end{array}$ & $\begin{array}{r}44.0^{*} \\
\pm 1.07\end{array}$ & & $\begin{array}{c}4.2 \\
+0.99\end{array}$ & $\begin{array}{l}42.9 \\
\pm 0.972\end{array}$ & & $\begin{array}{r}1.3^{*} \\
\pm 0.42\end{array}$ \\
\hline
\end{tabular}

*Significantly different from Set $I$ at the five per cent level by paired t-test. 
ence in the slopes decreased to $1.7 \pm 0.55$ litres/ $\mathrm{min} / \mathrm{mm} \mathrm{Hg}$, and for the third set of tests at about 95 minutes after ethanol, the mean difference in the slopes decreased further to $1.3 \pm 0.42$ litres/ $\mathrm{min} / \mathrm{mm} \mathrm{Hg}$. Both of the values after ethanol are significantly different from the control value at the five per cent probability level by paired t-testing. While the individual values of the differences in slopes showed an inverse correlation $(r=0.91)$ with the ethanol levels (mean value of before and after measurements in Table I) for the second set of tests, which was significant at the one per cent probability level, there was no such correlation for the third set of tests, at about 95 minutes after $(r=0.39)$. Since this difference in slopes is an index of the ventilatory response to simultaneously rising carbon dioxide and falling oxygen mediated by the peripheral chemoreceptors, it was concluded that ethanol had impaired this response.

Breath-by-breath graphs were also made of ventilation against end-tidal $\mathrm{Po}_{2}$ for the hypoxic rebreathing tests so that they could be compared by inspection. Each graph was fitted with a linear regression line. Figure 6 shows these graphs of volunteer S.S. for the hypoxic rebreathing tests of test sets I, II and III. These graphs are typical of the responses from most volunteers.

Table $V$ lists the slopes, intercepts and regression coefficients of ventilation against end-tidal $\mathrm{PO}_{2}$ for the hypoxic rebreathing tests of test sets $\mathrm{I}$, II and III. The mean slope $( \pm 1$ SEM) of the ventilation against end-tidal $\mathrm{PO}_{2}$ lines for the first hypoxic rebreathing tests under control conditions was $-1.42 \pm 0.193 \mathrm{litres} / \mathrm{min} / \mathrm{mm} \mathrm{Hg}$. For the second set of tests, at about 25 minutes after ethanol, the mean slope declined to $-0.919=$ 0.116 litres $/ \mathrm{min} / \mathrm{mm} \mathrm{Hg}$, and for the third set of tests, at about 95 minutes, the mean slope remained at $-1.02 \pm 0.134 \mathrm{litres} / \mathrm{min} / \mathrm{mm} \mathrm{Hg}$. While the first value after ethanol is significantly different from the control value at the five per cent probability level by paired t-testing, the second value was not. This slope is an index of the ventilatory response to simultaneously rising carbon dioxide and falling oxygen mediated by both the peripheral and central chemoreceptors, and its changes confirm those for the slopes of the ventilation against end-tidal $\mathrm{PCO}_{2}$ lines in the hypoxic rebreathing tests.

\section{Discussion}

The method that was used to measure the responsiveness of the peripheral chemoreceptors in

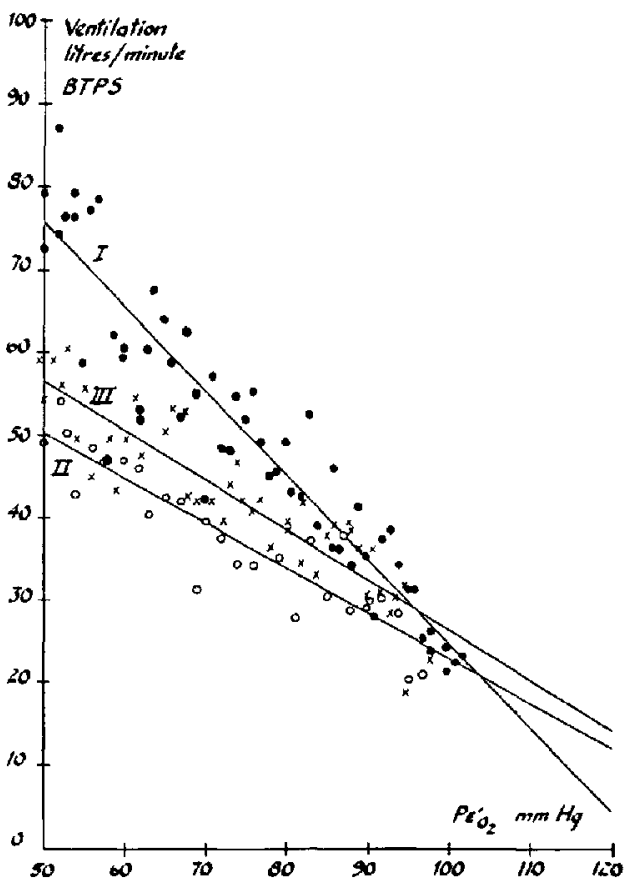

Figure 6. A plot of breath-by-breath values of ventilation in litres per minute (BTPS) versus end-tidal $\mathrm{PO}_{2}$ ( $\mathrm{PE}^{\prime} \mathrm{O}_{2}$ ) for volunteer S.S. during test set I (black circles), test set 1 ( (white circles) and test set III (crosses), hypoxic rebreathing tests.

these experiments was the ventilatory response to sinultaneously increasing hypoxia and hypercapnia. Since this method differs from previous peripheral chemoreceptor tests by Weil, ByrneQuinn, Sodal, Friesen, Underhill, Filley and Grover, ${ }^{11}$ and Rebuck and Campbell, ${ }^{12}$ which measure the ventilatory response to increasing hypoxia at constant levels of carbon dioxide, it requires a description of the principles which underly its rationale.

The ventilatory response to carbon dioxide and hypoxia, which is mediated by both central and peripheral chemoreceptors, can be modelled ${ }^{13}$ by dividing it into central and peripheral components which add to form the complete response. The central component is considered to be a simple fixed straight line relationship between ventilation and $\mathrm{PCO}_{2}$ which is independent of changes in $\mathrm{PO}_{2}$. The peripheral component is more complex. In this case, both carbon dioxide and hypoxia act as stimuli and are synergistic.

The peripheral component can be modelled as the sum of a response to carbon dioxide and a response to hypoxia. The response to hypoxia is considered to be a fixed, rectangular hyperbolic 


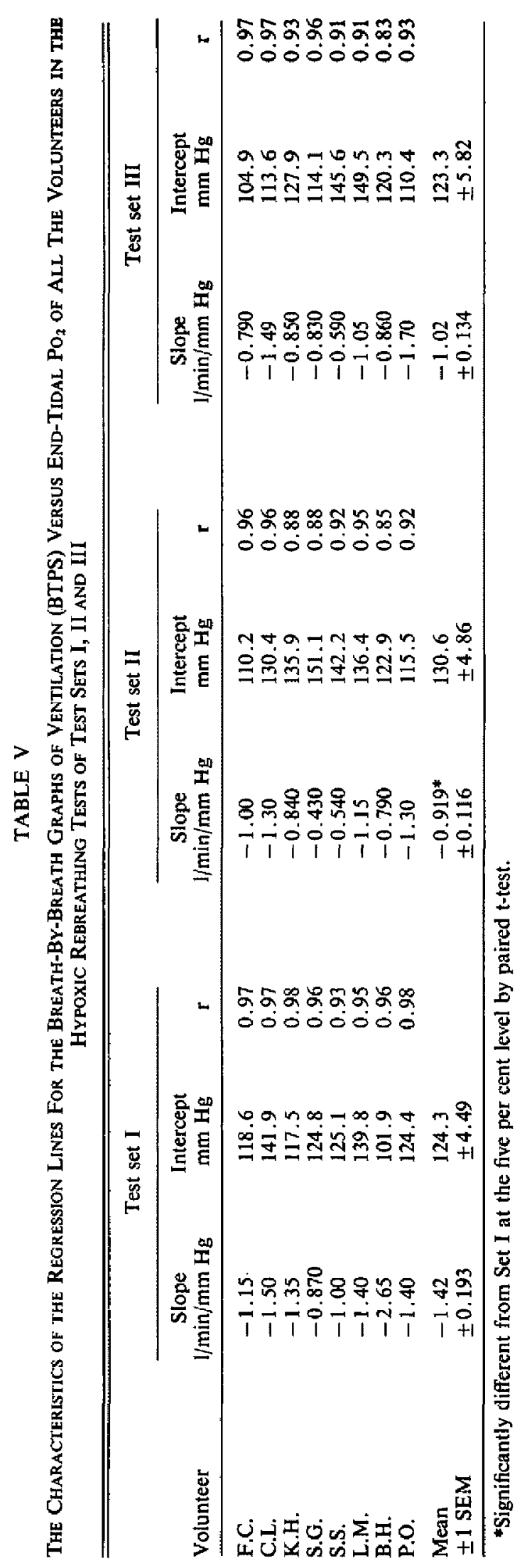


relation between ventilation and $\mathrm{PO}_{2}$ which is independent of changes in $\mathrm{PCO}_{2}$. The response to carbon dioxide is not fixed, however, but a straight line relation between ventilation and $\mathrm{PCO}_{2}$ whose slope (sensitivity) depends upon $\mathrm{PO}_{2}$. The relation between this slope and $\mathrm{PO}_{2}$ has the same rectangular hyperbolic shape as the ventilation- $\mathrm{PO}_{2}$ relation.

Such a model applied to the hypoxic rebreathing test would appear to generate a ventilation$\mathrm{PCO}_{2}$ relation which was curved rather than the straight lines found in this study. In fact, the model predicts a relation which is so slightly curved as to be virtually a straight line, with a slope approximately that for a constant $\mathrm{PO}_{2}$ of $6.67 \mathrm{kPa}(50 \mathrm{~mm} \mathrm{Hg})$. The straight line relation depends upon the linear rise in $\mathrm{PCO}_{2}$ and fall in $\mathrm{PO}_{2}$ with time during the hypoxic rebreathing test, the linkage of these rates of change through metabolism, and the lack of radical curvature in the chemoreceptor model for $\mathrm{Po}_{2}$ values above $6.67 \mathrm{kPa}(50 \mathrm{~mm} \mathrm{Hg})$. Although it would appear possible to achieve a constant $\mathrm{Po}_{2}$ in this test, by modifying the initial $\mathrm{PO}_{2}$ in the rebreathing bag and introducing an oxygen flow equal to metabolic consumption, such a modification requires further testing.

The hypoxic rebreathing test therefore has the advantages of linearity, moderate use of hypoxia and, most important, it mimics the clinical conditions under which the peripheral chemoreceptors provide their most valuable protection, that of simultaneously occurring hypoxia and hypercapnia. In addition, the test apparatus is simple. The disadvantage of the test is that it requires two breathing runs, although if the central ventilatory response is required then two tests are mandatory using any method.

The testing protocol used in this experiment was designed to test the effects of a moderate dose of ethanol on the ventilatory responses mediated by the central and peripheral chemoreceptors. Since the concentration of ethanol in cerebrospinal fluid may exceed that of blood during rising levels of ethanol (Forney, Hughes, Harger and Richards ${ }^{14}$ ), the rebreathing tests were timed to coincide with both the rising and falling leveis of ethanol. However, of those volunteers whose ethanol levels were rising during Test Set II and falling during Test Set III, no significant differences could be detected in the results at these differing times.

The ethanol levels attained showed considerabie variation between individuals. The variations in the ethanol levels was thought to reflect variation in the gastrointestinal absorption of ethanol since the dose was given orally rather than intravenously. However, it should be noted that Johnstone and Reier ${ }^{7}$ found a level of $40 \pm 5$ $\mathrm{mg} / 100 \mathrm{ml}$ immediately after a one hour intravenous perfusion of $0.35 \mathrm{ml} / \mathrm{kg}$ ethanol in six subjects compared with $57 \pm 8.4 \mathrm{mg} / 100 \mathrm{ml}$ found here. The variation between subjects is not very different, so that the differences in ethanol level between volunteers may not be so much due to differences in the absorption as differences in the distribution of ethanol.

The ventilatory responses showed a considerable variation between volunteers but the effects of the ethanol on these responses showed a clear trend. The hyperoxic ventilatory response to carbon dioxide mediated by the central chemoreceptors was neither significantly depressed in sensitivity (slope) nor shifted with respect to $\mathrm{PCO}_{2}\left(\mathrm{PCO}_{2}\right.$-intercept). The ventilatory response to simultaneous hypoxia and hypercapnia mediated by the peripheral chemoreceptors showed a significant depression in sensitivity (difference in the slopes of the hyperoxic and hypoxic rebreathing tests). The depression was not significantly different (paired $t$-test) between the rising and the falling levels of ethanol so that any differences in brain levels which may have occurred between those two times had no measureable effect on the peripheral chemoreceptor depression. Although the depression was proportional to the ethanol level initially ( $25 \mathrm{~min})$ it was not so later (95 min).

Sahn, et al. ${ }^{8}$ used the methods of Weil, et al." to test both central and peripheral chemoreceptor mediated responses. Their peak ethanol level was a mean of $110 \mathrm{mg} / 100 \mathrm{ml}(24 \mathrm{mmol} /$ litre $)$ at $20 \mathrm{~min}$ utes after ingestion compared with a mean peak value of $58 \mathrm{mg} / 100 \mathrm{ml}$ at 25 minutes in our volunteers. Their dose $(1 \mathrm{ml} / \mathrm{kg})$ was orally ingested over 30 minutes compared to the dose of 0.75 $\mathrm{ml} / \mathrm{kg}$ over 15 minutes for the volunteers in this study. Sahn, et al. ${ }^{8}$ found significant depression of the peripheral response at $\mathbf{2 0}$ minutes after ethanol, but not at 70 minutes, and a significant depression of the central response at 70 minutes, but not at 20 minutes after ethanol. These findings are in agreement with those presented here for the 20-minute time, but not for the 70-minute time. While this difference could be due to differences in measurement techniques, it would appear more likely that the higher ethanol levels could account for the different effects observed.

Johnstone and Reier ${ }^{7}$ tested only the central ventilatory response and they used several in- 
travenous doses of ethanol infused over 60 minutes. They found no depression of the ventilatory response (decrease in slope), but a dosedependent shift of the response to higher levels of carbon dioxide. At ethanol levels similar to those of our volunteers their central chemoreceptor mediated ventilatory responses showed no shift or decreased slope, in agreement with the findings presented here.

The results presented here show that for low levels of ethanol, which produce no significant depression of the ventilatory responses mediated by the central chemoreceptors, the responses mediated by the peripheral chemoreceptors are significantly depressed. Such depression could result from the action of ethanol at these doses on the complex peripheral chemoreflex arc or could be due to such diverse actions as central nervous system depression or alteration of lung mechanics. However, it would appear likely that the site of action is at the peripheral chemoreceptors themselves since the central chemoreflex arc, which shares the same pathway, remains unchanged at these levels of ethanol. The peripheral chemoreceptors themselves may be affected directly by ethanol, resulting in alterations in the neural activity of the receptors, or indirectly by a change in the blood flow through the carotid bodies (see the review by Torrance ${ }^{15}$ ). Since ethanol produces a centrally mediated vasodilation $^{16}$ it seems likely that the carotid body blood flow would be similarly increased. In this respect, the findings presented here may also be relevant to the depression of the peripheral chemoreflex by other drugs such as halothane which share the property of general vasodilation. Whether ethanol acts directly or indirectly is not known; however, our studies show that during mild ethanol intoxication the responsiveness of the peripheral ventilatory chemoreflex is significantly impaired.

\section{SUMmary}

The ventilatory responses mediated by the central and peripheral chemoreceptors were separately assessed in eight healthy volunteers before and after the oral ingestion of ethanol in a dose of $0.75 \mathrm{ml} / \mathrm{kg}$. No significant depression of the central response was observed, but a significant depression of the peripheral response was observed at 25 and 95 minutes after the consumption of ethanol. The peripheral chemoreceptor stimulus was the simultaneous increase of hypoxia and hypercapnia and this novel method is described.
RÉSUMÉ

La réponse respiratoire réflexe initiée par les chémorécepteurs centraux et périphériques a été étudiée de façon séparée chez huit volontaires en bonne santé, avant et après ingestion orale de $0.75 \mathrm{ml} / \mathrm{kilo}$ d'alcool éthylique.

On n'a pas observé de dépression significative du mécanisme central, mais une dépression significative de la réponse périphérique a été observée, 25 et 95 minutes après ingestion de l'alcool.

Comme stimulus des chémorécepteurs périphériques, on a utilisë une hypoxie et une hypercapnie simultanée et croissante. Cette nouvelle méthode est décrite.

\section{ACKNOWLEDGEMENTS}

The authors wish to acknowledge the financial support of the Health Sciences Committee of the Research Board, University of Toronto, and the advice of Dr. L. Spero, Department of Pharmacology, University of Toronto, in the completion of this project.

\section{REFERENCES}

I. Whitwam, J.G., Duffin, J., \& Triscott, A. The effect of halothane on ventilatory responses mediated by the peripheral chemoreceptors. Clin. Sci. 40: 13P (1971).

2. Duffin, J., Triscott, A., \& Whitwam, J.G. 'The effect of halothane and thiopentone on ventilatory responses mediated by the peripheral chemoreceptors in man. Br. J. Anaesth, 48: 975 (1976).

3. Mackenzie, J.F. \& HiLL, L. The influence of alcohol on the power to hold the breath and to work. J. Physiol. 4l: IV Proc. (1910).

4. Higains, H.L. Effect of alcohol on the respiration and the gaseous metabolism in man. J. Pharmacol. 9: 441 (1917).

5. Нітснсоск, F.A. Alterations in respiration caused by alcohol. Quart. J. of Studies on Alcohol 2:641 (1942).

6. JohNSTONE, R.E. \& WiTt, F.L. Respiratory effects of ethyl alcohol intoxication. J.A.M.A. 222: 486 (1972).

7. JohNSTONE, R.E. \& ReIER, C.E. Acute respiratory effects of ethanol in man. Clin. Pharmacol. and Therap. 14: 501 (1973)

8. Sahn, S.A., Lakshminarayan, S., Pierson, D.J., \& WEIL, J.V. Effect of ethanol on the ventilatory responses to oxygen and carbon dioxide in man. Clin. Sci. and Mol. Med. 49: 33 (1975).

9. DufFin, J. The chemical regulation of ventilation. Anaesthesia 26: 142(1971).

10. READ, D.J.C. A clinical method for assessing the ventilatory response to carbon dioxide. Aust. Ann. Med. 16: 20 (1967). 
11. Weil, J.V., Byrne-QuinN, E., Sodal, I.E., Friesen, W.O., Underhith, B., Filley, G.F., \& Grover, R.F. Hypoxic ventilatory drive in normal man. J. Clin. Invest. 49: 1061 (1970).

12. Rebuck, A.S. \& Campbell, E.J.M. A clinical method for assessing the ventilatory response to hypoxia. Amer. Rev. of Resp. Dis. 109:345 (1974).

13. Duffin, J. A mathematical model of the chemoreflex control of ventilation. Respir. Physiol. 15: 277 (1972).

14. Forney, R.B., hughes, F.W., Harger, R.N., \& RICHARDS, A.B. Alcohol distribution in the vascu- lar system. Quart. J. of Studies on Atcohol 25: 205 (1964).

15. Torrance, R.W. Arterial chemoreceptors. In: The MTP International Review of Science, Physiology Series One, Volume 2, Respiratory Physiology, edited by Widdicombe, J.G., London. Butterworths pp. 247-271 (1974).

16. Rutchie, J.M. The aliphatic alcohols. In: The Pharmacological Basis of Therapeutics, 4th ed., edited by Goodman, L.S., \& Gilman, A., Toronto, Collier-Macmillan pp 135-145 (1970). 